\title{
Thrombopoietin Receptor Agonists (TPO-RAs): Drug Class Considerations for Pharmacists
}

\author{
Jeffrey Gilreath ${ }^{1}$ (I) $\cdot$ Mimi Lo $^{2,3} \cdot$ Joseph Bubalo ${ }^{4}$
}

Accepted: 5 June 2021 / Published online: 23 June 2021

(c) The Author(s) 2021

\begin{abstract}
The thrombopoietin receptor agonists (TPO-RAs) romiplostim, eltrombopag, avatrombopag, and lusutrombopag carry unique US Food and Drug Administration (US FDA)- and European Medicines Agency (EMA)-approved indications and may be used to increase platelet counts in a variety of conditions. Current indications for available TPO-RAs include treatment of chronic immune thrombocytopenia (ITP) in cases of insufficient response to prior treatment (avatrombopag, eltrombopag, romiplostim), management of thrombocytopenia in adult patients with chronic liver disease who are scheduled to undergo a procedure (avatrombopag, lusutrombopag), management of severe aplastic anemia (eltrombopag), and management of thrombocytopenia associated with interferon-based therapy for hepatitis $\mathrm{C}$ (eltrombopag). Across current indications, pharmacists can assist in stabilizing platelet counts and help to reduce large undulations commonly seen when starting, stopping, or transitioning between these agents. If therapy modifications may benefit the patient, pharmacists should discuss possible changes with the patient's treatment team or treating physician. When used for ITP, romiplostim, eltrombopag, and avatrombopag stimulate TPO receptors on hematopoietic stem cells (also known as $c-M p l$, or CD110) to promote platelet production; however, romiplostim is the only TPO-RA that binds at the same site as endogenous TPO. These subtle mechanistic differences may explain why switching TPO-RA may be clinically advantageous in some situations. As pharmacists are called to counsel patients on TPO-RA use, a deep understanding of potential adverse events and management strategies, as well as appropriate monitoring, will increase the likelihood that patients meet their goals of therapy in the shortest timeframe. Other uses of TPO-RAs are also discussed in this review, including use following hematopoietic stem cell transplant, use in myelodysplastic syndrome, and use in chemotherapy-induced thrombocytopenia.
\end{abstract}

Jeffrey Gilreath

Jeffrey.Gilreath@hci.utah.edu

1 Department of Pharmacotherapy, Clinical Hematology/ Oncology Pharmacist, University of Utah Hospitals and Clinics Sugar House Clinic, Salt Lake City, UT, USA

2 Adult Hematology/Oncology/Blood and Marrow Transplant, University of California, San Francisco Medical Center, San Francisco, CA, USA

3 UCSF School of Pharmacy, San Francisco, CA, USA

4 Division of Hematology and Medical Oncology, and Oncology Clinical Pharmacist, OHSU Hospital and Clinics, Portland, OR, USA

\section{Key Points}

Thrombopoietin receptor agonists (TPO-RAs) offer different clinical opportunities based on their pharmacokinetic, pharmacodynamic, and mechanistic characteristics.

In addition to the safety and efficacy of each agent, pharmacists counseling patients on TPO-RA use should consider patient preference for route of administration, the need for stable platelet control and impact of dietary restrictions.

An in-depth knowledge of the TPO-RA class will empower pharmacists and other healthcare professionals to participate in appropriate decision making with individual patients. 


\section{Introduction}

Understanding of thrombopoiesis, or the formation of the platelet component of blood, has improved over time, with the recognition of thrombopoietin (TPO) as the primary regulator of platelet production, renewal, and expansion [1]. Although the existence of TPO was first described in the literature in 1958, it was not until 1994 that basic research uncovered the gene encoding the receptor, $\mathrm{c}-\mathrm{Mpl}$, which led to the discovery of its endogenous ligand, TPO [1-3]. These discoveries, paired with the knowledge of impaired thrombopoiesis in patients with immune thrombocytopenia (ITP), led to research on TPO receptor agonists (TPO-RAs) [4, 5] and subsequent clinical trials leading to their approval [6-11].

This review first provides an in-depth look at available TPO-RA options for second-line treatment of ITP in the adult and pediatric populations and addresses issues that are relevant from a pharmacist's perspective, including their therapeutic and safety profile, and key considerations for engaging patients in the decision-making process. This review also discusses the use of TPO-RAs in severe aplastic anemia, adults with chronic liver disease who are scheduled to undergo a procedure, and off-label uses such as use following hematopoietic stem-cell transplant, in myelodysplastic syndromes, and in chemotherapy-induced thrombocytopenia.

\section{Thrombopoietin Receptor Agonists (TPO-RAs) in Immune Thrombocytopenia (ITP)}

Pathologically, ITP is classically characterized by an increase in platelet destruction and decrease in platelet production (due to inhibition of megakaryocyte function) $[12,13]$. ITP is a diagnosis of exclusion, relying on clinical and laboratory indicators including a platelet count $<100 \times 10^{9} / \mathrm{L}$. A definitive diagnosis of ITP also requires exclusion of other causes of thrombocytopenia [14]. Acute ITP, or newly diagnosed ITP, may be characterized by disease $<3$ months from diagnosis; persistent ITP refers to disease that is 3 months to 1 year from diagnosis; and chronic ITP refers to thrombocytopenia persisting for 12 or more months after diagnosis [15, 16]. The International Working Group (IWG) classifies ITP as refractory when primary ITP has been confirmed by exclusion of other potential secondary causes of thrombocytopenia, patients are unresponsive to splenectomy or experience relapse following splenectomy, and patients require rescue therapy for clinically significant bleeding [16].
Although not all patients with ITP require second-line therapy, current US and international guidelines recommend use of TPO-RAs as one option among several others (e.g., rituximab, splenectomy) for second-line treatment of ITP following first-line treatment with intravenous immunoglobulin G (IV IgG), corticosteroids, or anti-D immune globulin $[4,5]$. In evaluating TPO-RAs, pharmacists should take into account expected response rates, onset of action, patient-specific dosing, cost, considerations for combination therapy in treatment-refractory patients, relevant safety characteristics, and, on occasion, evidence in support of switching agents when current therapy fails to meet goals [17].

\subsection{Thrombopoietin and Platelet Life Cycle}

The TPO receptor (also known as $c-M p l$ or CD110) is a 635 -amino-acid protein encoded by the $c-M p l$ gene. The TPO receptor has three functional domains including an extracellular cytokine binding region, a transmembrane domain, and a cytoplasmic domain that binds to signaling molecules including Janus kinases (JAKs) and signal transducer and activator of transcription proteins (STATs) [18]. The TPO receptor ligand, thrombopoietin, is produced primarily in the liver but also in the kidneys and bone marrow. It binds to TPO receptors on megakaryocytes, hematopoietic stem cells, and platelets themselves [2, 19, 20]. TPO stimulates proliferation and differentiation of megakaryocytes, resulting in increased platelet production [18, 21]. Regulation of endogenously produced thrombopoietin levels relies on a feedback loop involving the Ashwell-Morrell receptor expressed on hepatocytes. As a result of reduced steric hindrance, these receptors gain the ability to recognize aged platelets that have lost sialic acid residues. This resultant clearance of desialylated platelets from circulation by hepatocytes triggers hepatic production of thrombopoietin [22].

The pathophysiology of ITP is thought to primarily disrupt the platelet life cycle through generation of autoantibodies and platelet-reactive CD8+ T cells, which act to both reduce platelet production and increase clearance of pre-existing platelets from circulation. Macrophages and dendritic cells may also be involved in sensitizing $\mathrm{T}$ cells to platelet fragments [19, 21, 23-25]. Although romiplostim competes for the same receptor site as endogenous thrombopoietin, eltrombopag, avatrombopag, and lusutrombopag bind to the transmembrane region of the TPO receptor to activate the TPO receptor noncompetitively [26-29]. Pharmacologic characteristics of TPO-RAs are summarized in Table 1 [6, 8, 17, 27-34].

\subsection{Potency Comparisons of TPO-RAs in ITP}

In ITP, the relative potency of TPO-RAs differs based on patient- and treatment-related factors. Specifically, in 


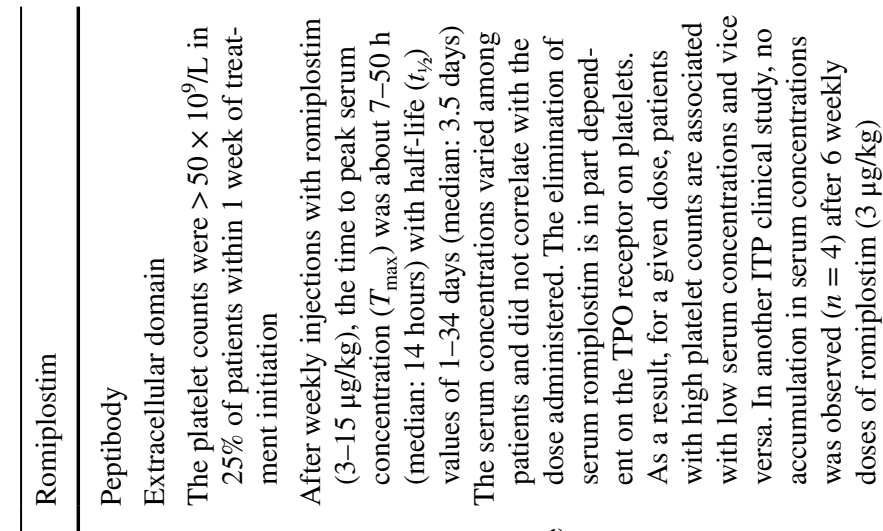

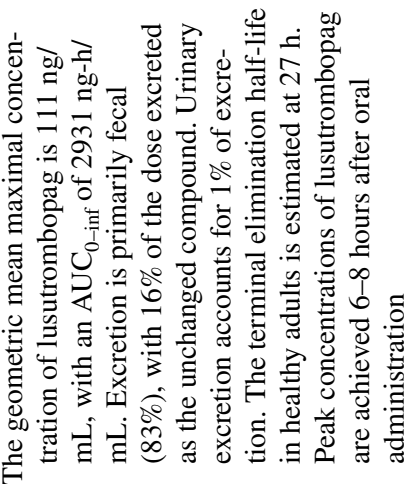

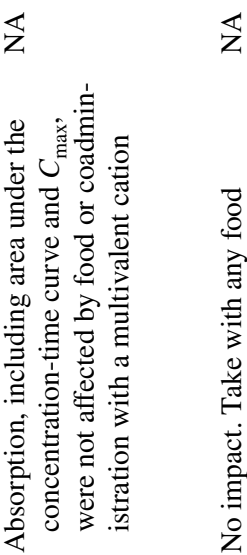

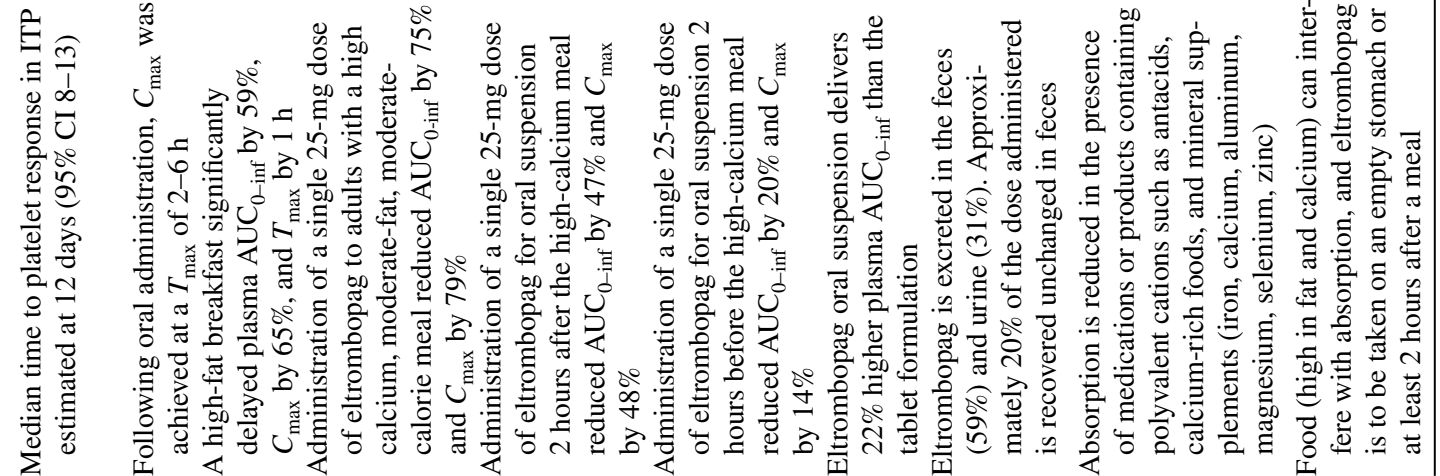

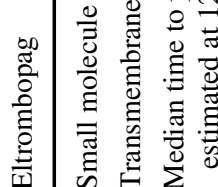
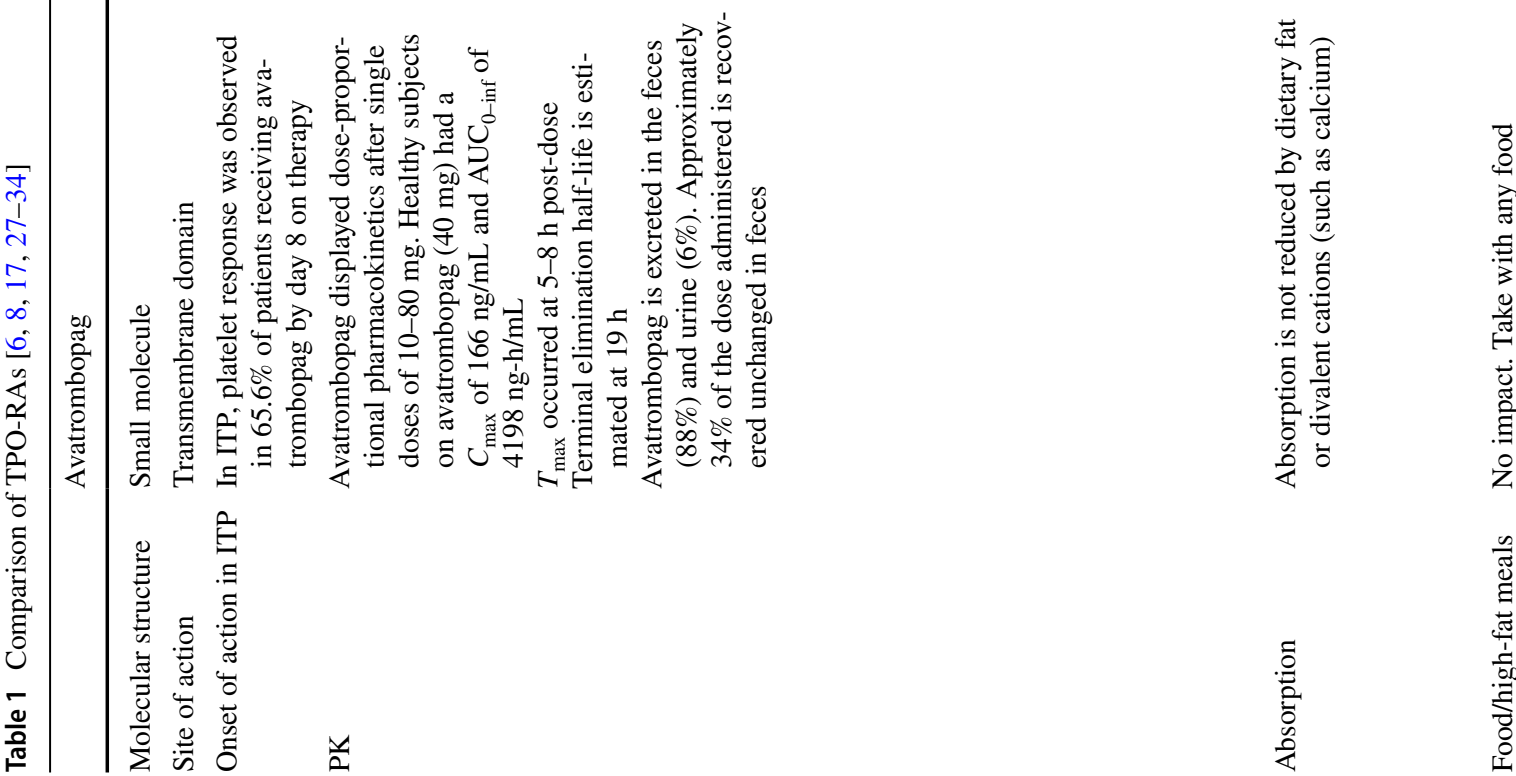
patients with ITP, lower endogenous TPO levels $(\leq 100 \mathrm{pg}$ / $\mathrm{mL}$ as assessed by an enzyme-linked immunosorbent assay) predict for an increased probability of response to eltrombopag and romiplostim, as compared with higher TPO levels $(>200 \mathrm{pg} / \mathrm{mL}$ ) [17]. This is consistent with an analysis of phase III data (ClinicalTrials.gov identifier NCT01438840) with avatrombopag showing a relationship between efficacy and baseline TPO levels. In this analysis, there was a numerical trend in baseline platelet count and response (i.e., platelet level $\geq 50 \times 10^{9} / \mathrm{L}$ that is also $20 \times 10^{9} / \mathrm{L}$ higher than baseline) decreasing from $71 \%$ in 18 patients with low TPO levels $(<115 \mathrm{pg} / \mathrm{mL}), 45 \%$ in eight patients with normal TPO levels (115-228 pg/mL), and $15 \%$ in five patients with high TPO levels ( $>228 \mathrm{pg} / \mathrm{mL}$ ) [35]. Peak platelet counts with maximal doses of romiplostim were 8-10 times higher than those achieved with eltrombopag, and peak platelet counts with maximal doses of avatrombopag were 3-5 times higher than those achieved with eltrombopag [17].

Although peak platelet counts may be higher in patients receiving romiplostim versus the orally administered TPORAs avatrombopag and eltrombopag, exaggerated pharmacologic effects with romiplostim may lead to wide swings in platelet counts, resulting in difficulties in dosage adjustment. These difficulties are compounded by the fact that romiplostim is only approved for use in health care settings in the United States, whereas approval extends to home administration in the European Union [31,36]. Gilreath et al. presented two cases of patients with chronic ITP in whom stable platelet counts were achieved using a modified dosing regimen of romiplostim. In each case, following romiplostim drug label dosing recommendations led to unexpected supratherapeutic platelet counts as well as subtherapeutic platelet counts that required rescue therapy (IV IgG) for severe thrombocytopenia. In patients with supratherapeutic platelet counts, rather than discontinuing treatment, the authors decreased the dose by $10-20 \%$ rather than a set $\mu \mathrm{g} / \mathrm{kg}$ decrement. Authors based this on the trend established by prior platelet count data over the preceding weeks (in one case, using a dose of $6.4 \mu \mathrm{g}$ / $\mathrm{kg}$ weekly) [37]. Current recommendations and prescribing information for romiplostim do not take into account trends in platelet count reduction and currently recommend interrupting romiplostim dosing for patients with platelet counts $>400 \times 10^{9} / \mathrm{L}$ [31]. Pharmacists aware of this pharmacokinetic/pharmacodynamic disconnect may be able to help avoid rebound thrombocytopenia in some patients.

\subsection{Efficacy of TPO-RAs in ITP in Adults}

\subsubsection{Methods}

Available TPO-RAs approved for use in ITP include avatrombopag, eltrombopag, and romiplostim. In each of the phase III trials establishing treatment safety and efficacy, the 
double-blind core treatment period was 6 months in duration [6-8]. In all three trials, efficacy evaluations included rates of the median cumulative weeks of response (cumulative weeks with platelet counts $\geq 50 \times 10^{9} / \mathrm{L}$ ), early platelet response (platelet count $\geq 50 \times 10^{9} / \mathrm{L}$ at day 8 ), and durable response (platelet counts $\geq 50 \times 10^{9} / \mathrm{L}$ in $\geq 6$ of the final 8 weeks of treatment during the core phase). Although there were some similarities in trial design, notable differences between end point definitions across trials did exist [6-8]. For example, patients who had received prior rescue therapy (i.e., use of any additional ITP therapy) were disqualified from being counted as weekly responders during the avatrombopag study [6], but could be counted as weekly responders in the eltrombopag trial regardless of prior rescue therapy use [7], and could be counted as weekly responders in patients who used rescue therapy $>8$ weeks prior to response in the romiplostim trial [8].

\subsubsection{Avatrombopag}

In the phase III study of avatrombopag, 49 patients were randomized in a 2:1 ratio to avatrombopag $20 \mathrm{mg}$ daily or placebo. For the primary outcome of the avatrombopag pivotal trial, the median cumulative weeks of response without rescue therapy was 12.4 weeks with avatrombopag versus 0 weeks with placebo $(p<0.0001)$. Early platelet response, which was a predefined secondary end point defined as a platelet count $\geq 50 \times 10^{9} / \mathrm{L}$ at day 8 , was observed in $65.6 \%$ of patients receiving avatrombopag versus $0 \%$ of patients receiving placebo $(p<0.0001)$. On the exploratory end point of durable response, attainment of durable response (i.e., platelet counts $\geq 50 \times 10^{9} / \mathrm{L}$ in $\geq 6$ of the final 8 weeks of treatment during the core phase and no use of rescue therapy) was significantly more likely with avatrombopag versus placebo (34.4\% vs $0.0 \% ; p=0.009)$ [6].

\subsubsection{Eltrombopag}

In a phase III study of eltrombopag, 197 patients were randomized in a $2: 1$ ratio to eltrombopag $50 \mathrm{mg}$ daily or placebo. The mean number of weeks of platelet response reported in patients receiving eltrombopag was 14.3 weeks [7]. Although day 8 platelet response rates were not explicitly reported in the phase III trial of eltrombopag in ITP, median day 8 response rates with eltrombopag $50 \mathrm{mg}$ and $75 \mathrm{mg}$ were $44 \%$ and $62 \%$, respectively, in an earlier phase II study of eltrombopag, all of which were higher than the $<10 \%$ rate of platelet response with placebo [38]. In a posthoc analysis of available data, durable response (i.e., platelet counts $\geq 50 \times 10^{9} / \mathrm{L}$ in $\geq 6$ of the final 8 weeks of treatment during the core phase regardless of prior rescue therapy use) occurred in $60 \%$ of patients (57/95) randomized to eltrombopag who completed the core study versus $10 \%$ (4/39) of patients randomized to placebo $(p<0.0001)$. Overall rates of attainment of durable platelet response were $51 \%(19 / 37)$ in splenectomized patients receiving eltrombopag and $66 \%$ (38/58) in patients receiving eltrombopag who had not undergone splenectomy [7].

\subsubsection{Romiplostim}

Romiplostim was evaluated in two parallel phase III trials of splenectomized $(n=63)$ and non-splenectomized ITP patients $(n=62)$. In each trial, patients were randomized to romiplostim or placebo in a $2: 1$ ratio. The $1-\mu \mathrm{g} / \mathrm{kg}$ starting dose of romiplostim was increased by $1-2 \mu \mathrm{g} / \mathrm{kg}$ every week or every 2 weeks depending on platelet counts, with a maximum allowed weekly dose of $15 \mu \mathrm{g} / \mathrm{kg}$. The mean number of weeks of platelet response with romiplostim versus placebo was 13.8 versus 0.8 weeks $(p<0.0001)$ in the splenectomized group and 15.2 versus 0.8 weeks $(p<0.0001)$ in the non-splenectomized group. Early platelet response occurred in $25 \%$ of patients within 1 week of romiplostim initiation. The primary outcome measure of durable response (platelet counts $\geq 50 \times 10^{9} / \mathrm{L}$ in $\geq 6$ of the final 8 weeks of treatment during the core phase and no use of rescue therapy during the prior 8 weeks) was achieved in $38 \%$ of splenectomized patients $(16 / 42)$ receiving romiplostim versus $0 \%(0 / 21)$ of splenectomized patients receiving placebo $(p=0.0013)$. In non-splenectomized patients receiving romiplostim, the primary outcome of durable response was achieved in $61 \%$ of patients $(25 / 41)$ versus $5 \%$ of patients $(1 / 21)$ receiving placebo $(p<0.0001)[8]$.

\subsection{Switching Between TPO-RAs}

TPO-RAs differ in their molecular structure, pharmacokinetic profile, and the manner in which they stimulate the TPO receptor. Unlike romiplostim, avatrombopag and eltrombopag do not compete for the endogenous TPO receptor binding site $[28,39]$. Binding to the TPO-receptor, $c-M p l$, may induce greater Akt pathway activation compared with JAK/STAT, thereby inducing megakaryocytic proliferation to a greater degree than platelet production [39]. Although adherence to dietary restrictions while taking eltrombopag therapy may explain some differences in efficacy between TPO-RAs, subtle mechanistic differences appear to have clinically relevant effects, as patients who experience toxicities or lack of efficacy with one TPO-RA may benefit by switching to an alternate TPO-RA. In one study of 46 patients switching between TPO-RAs, the most common reasons for the switch included lack of efficacy of the first TPO-RA followed by platelet count fluctuation, side effects, and patient preference. Although suboptimal efficacy with an initial TPO-RA affects a minority of patients, pharmacists should note that patients who do not exhibit 
a response to one TPO-RA may exhibit a response to an alternative agent. For example, in romiplostim nonresponders, $46 \%$ of patients experienced a response in the platelet count after switching to eltrombopag. Similarly, $80 \%$ of eltrombopag nonresponders who switched to romiplostim responded to the new treatment [40].

A pooled analysis by González-Porras et al. of data from 18 publications identified lack of efficacy (defined by sustained platelet counts $<30,000 / \mu \mathrm{L}$ ) as the reason for switching to another TPO-RA in 58\% of patients. In patients who switched as a result of efficacy concerns, nearly two-thirds (65\%) of patients who did not respond to a prior TPO-RA responded to an alternative TPO-RA. Among patients who switched for reasons unrelated to efficacy, $93 \%$ of patients maintained their response with the subsequent TPO-RA, with response defined as sustained platelet counts $\geq 30,000$ / $\mu \mathrm{L}$. Overall, across trials, $78 \%$ of patients achieved or maintained a platelet response [39]. Outcomes were similar regardless of which TPO-RA was used initially, with a higher rate of response when switched due to adverse events or patient preference versus lack of efficacy [39, 41]. A 4-week trial at the maximum recommended dose is generally considered adequate before transitioning between TPORAs or adding on a second agent to augment efficacy (e.g., immunosuppressive therapy or corticosteroid) [39].

\section{Treatment and Dispensing Considerations}

\subsection{ITP Treatment Considerations for Pharmacists}

The updated American Society of Hematology (ASH) 2019 guidelines for ITP suggest second-line treatment with a TPO-RA, splenectomy, or rituximab in corticosteroiddependent or corticosteroid-unresponsive adults with at least a 3-month history of ITP. Although the choice should be individualized, the guidelines generally recommend use of rituximab over splenectomy and treatment with a TPO-RA over rituximab [4]. Pharmacists should note that receipt of rituximab may diminish vaccine response for 6-12 months after receipt. It is therefore imperative that patients receive any vaccinations that are due prior to the administration of rituximab and consider the diminished response if patients will be travelling to an area where specific vaccines are recommended prior to travel $[41,42]$. Thus, selection of treatments requires consideration of patient age, route of administration, diet, monitoring needs, and drug cost, and involves shared decision making by the patient, family, and physician. The pharmacist's role in patient education and counseling is important for shared decision making while considering various aspects including the duration of ITP therapy, corresponding adverse effect profile, route of administration, frequency of bleeding episodes requiring hospitalization or rescue medication, patient age, comorbidities, medical and social support, patient preferences, cost, and availability [4, 5].

In this discussion, it is important to recognize that patients and physicians have different perceptions and priorities with regard to treatments in ITP. For example, although physicians perceive bleeding as the most important factor in quality of life, adult patients with ITP report that low energy levels and limitations on the ability to perform daily tasks were more salient. Nearly half $(43 \%)$ of working patients reported that ITP affected their productivity at work, and approximately one-fifth (21\%) reported considering termination of their employment due to ITP [43]. Effects on daily activities and quality of life are a generally underreported concern. TPO-RAs have been shown to increase platelet counts and reduce bleeding. Interestingly, the most frequently cited reason for initiating a second-line therapy in children with ITP was quality of life (e.g., limitations in daily tasks and reduced energy levels) with $73 \%$ of clinicians reporting this as a reason to treat. Bleeding was less commonly cited as a factor in initiating therapy (15-18\%) [44]. Pharmacists who understand how patient preferences affect the decision to initiate and continue specific types of therapy in ITP may wish to include these counseling points to inform patients of their options and help bridge this disconnect [43].

\subsection{Administration Considerations}

It is particularly important for pharmacists to understand and communicate restrictions on use of specific TPO-RAs with food. Administration of eltrombopag tablets with food versus in a fasted state reduced bioavailability as assessed by area under the concentration-time curve by $59 \%$ (geometric mean ratio [GMR]: $0.41 ; 90 \%$ confidence interval [CI] 0.36-0.46), and administration of eltrombopag tablets with aluminum hydroxide and magnesium carbonate antacid tablets reduced bioavailability by approximately $70 \%$ (GMR 0.30 ; 90\% CI 0.24-0.36) [45]. When administered with a high-calcium meal or within 2 hours of an ordinary meal, the oral suspension formulation of eltrombopag showed reduced bioavailability versus the tablet formulation of eltrombopag. Specifically, least square mean GMR of area under the concentration-time curve was reduced by $75 \%$ (GMR 0.254 ; $90 \%$ CI $0.224-0.287$ ) with the oral suspension versus the tablet formulation when administered with a high-calcium meal and by $20 \%$ (GMR $0.804 ; 90 \%$ CI $0.711-0.908$ ) when administered $2 \mathrm{~h}$ before an ordinary meal [46]. The product labeling for eltrombopag recommends that doses of eltrombopag be taken either without a meal or with a meal containing $50 \mathrm{mg}$ of calcium or less. Consistent with concerns over calcium-food interactions, eltrombopag should be taken either 2 hours before or 4 hours after any product containing polyvalent cations (e.g., calcium, iron, magnesium) [30]. 
Studies of avatrombopag bioavailability found no effect of food on the ultimate extent of avatrombopag absorption, and there are no restrictions on taking avatrombopag with polyvalent cations [28, 47]. The product labeling for avatrombopag recommends taking doses with food [28]. Although it is not currently indicated for use in ITP, lusutrombopag may be taken with or without food [29].

\subsection{Dispensing Considerations}

The only injectable TPO-RA, romiplostim, is supplied in vials containing $125 \mu \mathrm{g}, 250 \mu \mathrm{g}$, or $500 \mu \mathrm{g}$. Although romiplostim is usually reconstituted and administered in a health care setting through subcutaneous injection [31], it is possible to procure this agent for home use. In this instance, extensive training must be performed to ensure that the adequate amount of diluent is used to dissolve the lyophilized powder and that the dosage is based on the final concentration as stated in the drug label, not based upon how much volume was used for reconstitution. Additionally, because volume sizes of one milliliter or less are common, great care must be taken to avoid pushing the plunger on the syringe so as to avoid loss of any product [31].

Oral TPO-RAs approved in ITP include eltrombopag and avatrombopag. Eltrombopag is available in tablets with four dosage strengths of $12.5 \mathrm{mg}, 25 \mathrm{mg}, 50 \mathrm{mg}$, and $75 \mathrm{mg}$, whereas the oral suspension is available in $12.5-\mathrm{mg}$ and 25-mg packets to be reconstituted immediately prior to administration [30]. When dispensing eltrombopag, pharmacists should be aware that eltrombopag dosing may need to be reduced in patients who are of Asian ancestry (i.e., Chinese, Japanese, Taiwanese, or Korean) [30]. Unlike other TPO-RAs, avatrombopag is supplied only as $20-\mathrm{mg}$ tablets for oral use. Because there is only one dosage strength for avatrombopag, downward titration of the dose may not immediately require a new prescription. Importantly, a new prescription is always required when titrating the dose to higher levels [28]. Note that tablets of avatrombopag should be stored in the original blister pack and eltrombopag should be dispensed in the original bottle. Current data are not robust enough to make a definitive recommendation on the use of TPO-RAs in pregnancy or lactation; benefits versus risks must be weighed for both mother and baby [48]. Dispensing information including associated toxicities is compiled in Table 2 [28-31, 37, 49-57].

\subsection{History of Risk Evaluation and Management System (REMS) Program}

Risk Evaluation and Management System (REMS) exists to inform appropriate risk-benefit decisions to ensure safe use of specific medications. Although a REMS program existed for romiplostim and eltrombopag, this requirement was lifted for both products in December 2011. These risk management plans were in place to mitigate the risk of certain adverse events such as hepatotoxicity and bone marrow fibrosis, monitor the risk of hematologic malignancy progression in patients with myelodysplastic syndrome (MDS), and monitor for cases of hemorrhage resulting from worsening thrombocytopenia in patients with ITP [58]. Pharmacists should continue to counsel patients on the potential serious risks that may occur with TPO-RAs and refer patients to medication guides. A modified REMS program is still in effect that includes a communication plan to inform health care professionals about the potential for adverse events associated with treatment $[59,60]$.

\subsection{Extemporaneous Compounding}

Although avatrombopag and eltrombopag are administered orally, in some cases, compounding medications for oral administration in patients who cannot swallow an intact dosage form may be necessary. For these patients, eltrombopag is available as tablets and as an oral suspension. The eltrombopag oral suspension must be reconstituted with water prior to use (not hot water) and should be administered immediately and discarded if more than 30 minutes have elapsed since reconstitution [30]. It is currently not recommended to split, crush, or mix eltrombopag with food or liquids, as there are currently no published studies evaluating these types of manipulations [30, 45]. Stability data in food are available with avatrombopag. Finely crushed avatrombopag is stable for 30 minutes when mixed with whole milk yogurt or chocolate pudding. Recovery of avatrombopag in these foods was within $5 \%$ of the labeled amount, which is consistent with regulatory guidance on the administration of medications in a food vehicle [49].

\subsection{Drug Interactions}

TPO-RAs taken orally may be affected when co-administered with other drugs and require a dose adjustment. Patients must be advised to report use of any concomitant prescription or nonprescription medications or dietary supplements. Table 3 provides a list of the most common drug interactions observed [28-31].

\subsection{Adverse Events with TPO-RAs in ITP}

\subsubsection{Avatrombopag-Common Adverse Events}

TPO-RAs are generally tolerated well in patients with ITP. In a pooled analysis of clinical trials of avatrombopag in adult patients with chronic ITP, adverse events reported in $\geq 10 \%$ of patients included headache (31\%), fatigue ( $28 \%$ ), contusion (26\%), epistaxis (19\%), upper respiratory tract 


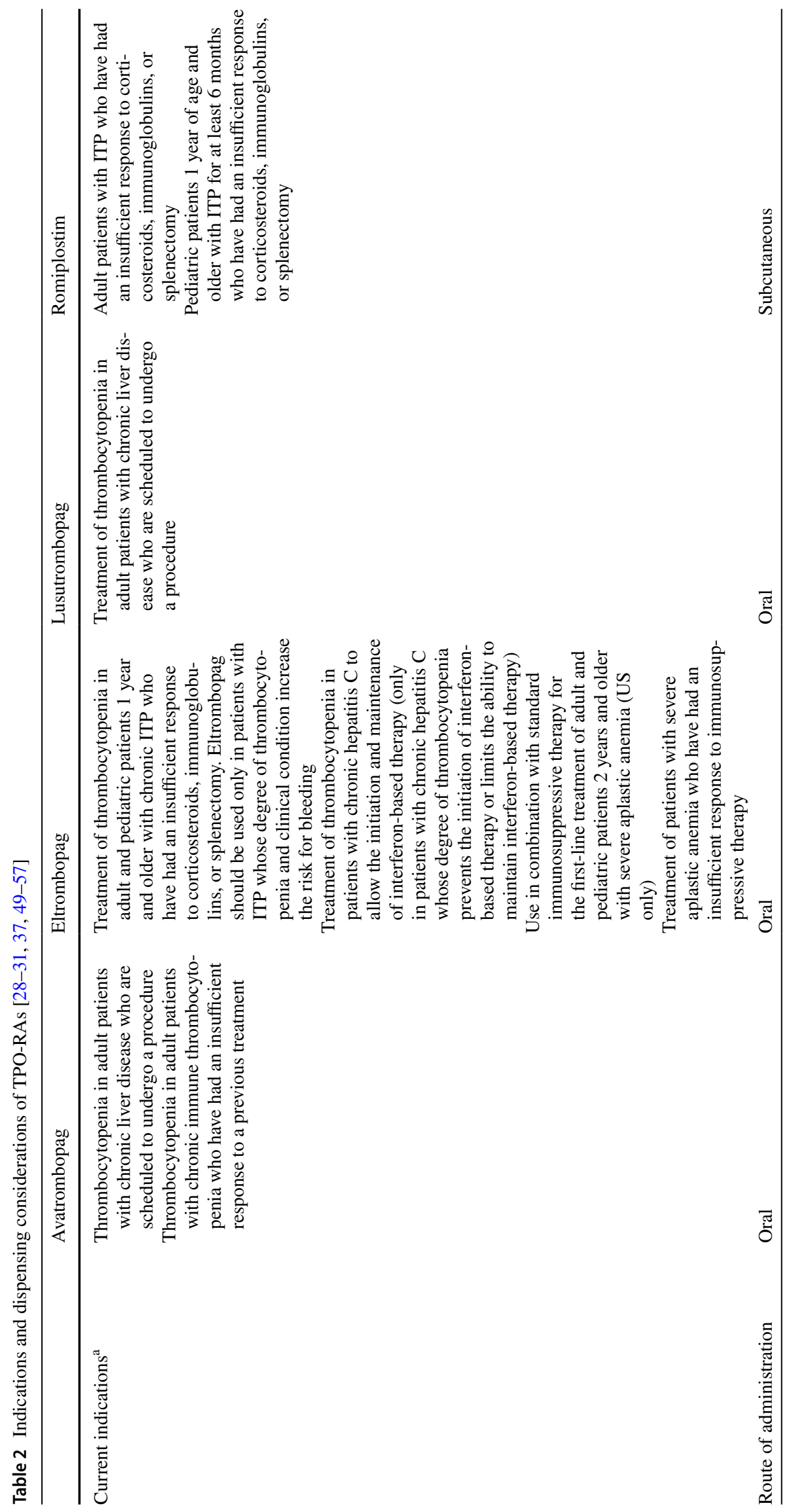




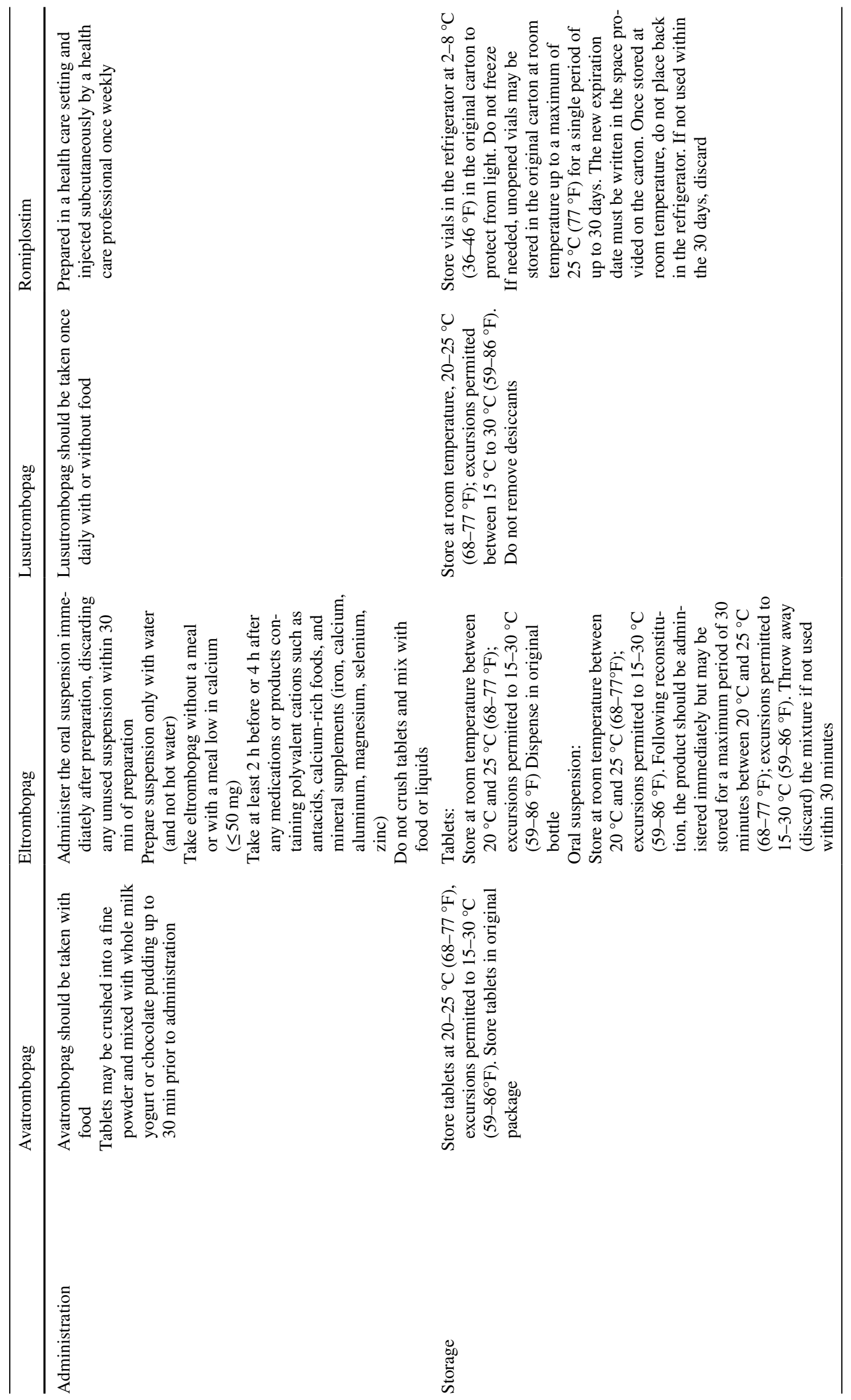




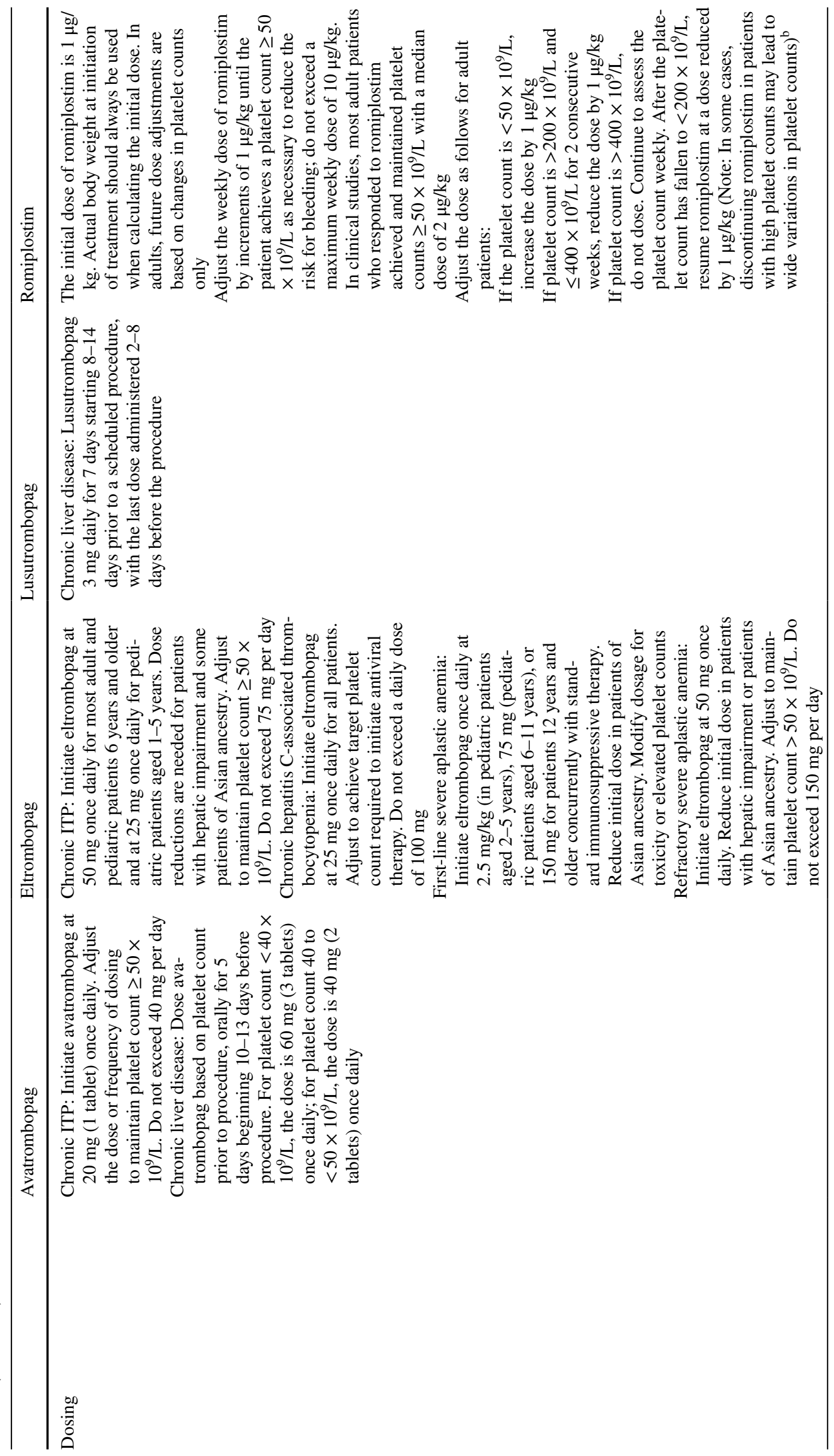




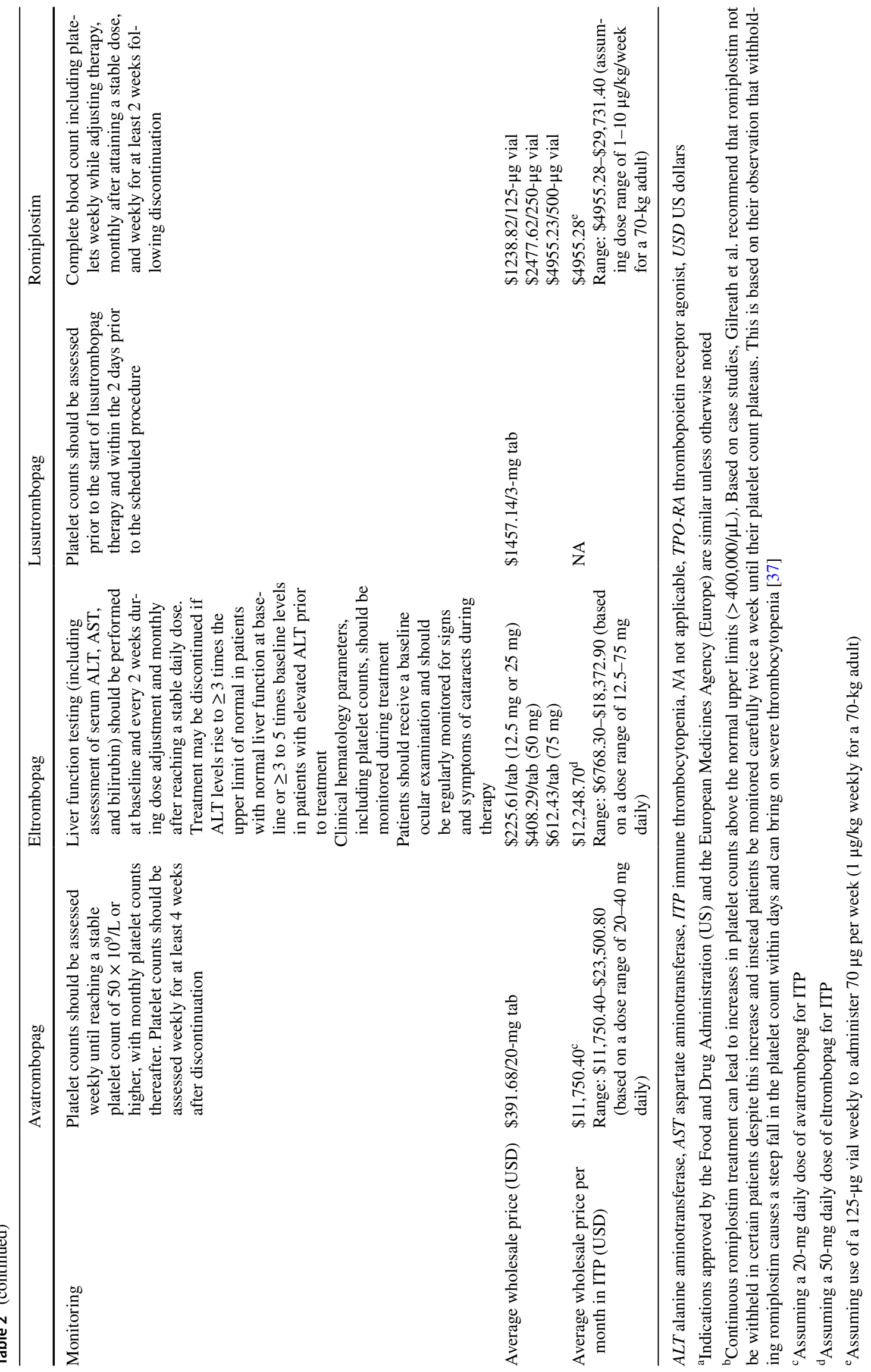


infection (15\%), arthralgia (13\%), gingival bleeding (13\%), petechiae (11\%), and nasopharyngitis (10\%) [28].

\subsubsection{Eltrombopag-Common Adverse Events}

In adult patients with chronic ITP, the most common adverse reactions reported in at least $3 \%$ of patients were eltrombopag-included headache $(10 \%)$, increased alanine aminotransferase $(5 \%)$, increased aspartate aminotransferase $(5 \%)$, cataract (5\%), fatigue (5\%), blood bilirubin increased (4\%), nausea (4\%), and diarrhea (3\%) [30].

\subsubsection{Romiplostim—Common Adverse Events}

In two pooled trials of romiplostim in ITP, the most commonly reported side effects reported in $\geq 5 \%$ of patients were arthralgia (26\%), myalgia (14\%), pain in extremity (13\%), shoulder pain (8\%), dizziness (17\%), paresthesia $(6 \%)$, insomnia (16\%), abdominal pain (11\%), and dyspepsia $(7 \%)$ [31].

The safety profiles of TPO-RAs are not superimposable. For example, adverse events such as cataracts and elevated transaminase levels are more commonly seen with eltrombopag. Certain potential adverse events, such as neutralizing antibody development, would only be possible with romiplostim [27].

\subsubsection{Thromboembolic Events}

Although ITP is associated with an elevated risk of thrombosis, thrombotic and thromboembolic complications are a possible adverse event with TPO-RAs, and patients treated with TPO-RAs should be monitored for thromboembolic events. Some long-term nonrandomized studies have suggested that patients with ITP have a modestly higher rate of thrombosis when treated with a TPO-RA than with an immunosuppressant [17]. The occurrence of thromboembolic events in long-term studies of avatrombopag, eltrombopag, and romiplostim in patients with ITP are comparable and have been estimated at approximately $6 \%$ to $7 \%$ across agents, with no clear association between platelet counts and risk of thrombosis [28, 30, 61-63]. According to international guidance, although TPO-RAs may be associated with arterial and venous thrombosis as a class warning, the rate of thromboembolic events was not elevated versus placebo in long-term (i.e., $\geq 6$ month) clinical trials of avatrombopag or eltrombopag [5, 6, 62]. Of note, however, thromboembolic event risk may be elevated versus placebo in patients receiving romiplostim, particularly in patients 60 years or older [5, 63]. 


\subsubsection{Reticulin Fibrosis}

Data from a large number of patients treated with TPO-RAs demonstrate a low risk of generally reversible bone marrow reticulin fibrosis without an increased risk of collagen fibrosis [17]. The risk of progression to myeloid malignancies is also low in these patients. In most cases, the grade of fibrosis does not change with TPO-RA treatment, but a slight nonprogressive reticulin fibrosis is observed in $10-50 \%$ of cases (i.e., grade 1 or Baumeister grade $<2$ ). Severe grades of reticulin fibrosis are very rare across studies of TPO-RAs [27].

\subsubsection{Transaminase Elevation}

Transaminase elevation may occur in up to $10 \%$ of patients taking eltrombopag and is typically seen in the first year of treatment, with hyperbilirubinemia occurring in approximately $4 \%$ of patients with long-term use [27, 30]. Importantly, the US Food and Drug Administration (US FDA)-approved dose of eltrombopag for severe aplastic anemia, $150 \mathrm{mg}$ daily for 6 months for patients 12 years and older, may cause skin and eye discoloration mimicking a jaundice-like state. Liver function tests along with iron indices should be examined to determine the cause. In a pooled analysis of four clinical studies of avatrombopag enrolling a total of 128 subjects, shifts in liver function tests to grade 2 or 3 abnormalities occurred in seven (5.5\%) patients, with no cases of grade 4 abnormalities observed or any increases in bilirubin and no signal of avatrombopag-induced hepatotoxicity identified [64]. With the exception of cases of portal vein thrombosis in patients with chronic liver disease, romiplostim does not appear to be associated with liver function abnormalities [31]. Unlike eltrombopag, romiplostim and avatrombopag do not require monitoring of liver function tests during therapy [28-31].

\subsubsection{Ocular Abnormalities}

Cataracts have been reported with eltrombopag in patients with chronic ITP across three pooled trials but at an equal rate to that observed in the placebo group (7\% vs 7\%) [30]. In the case of romiplostim, an integrated safety analysis integrating data from 14 clinical studies identified 34 cases of cataracts ( 2.2 cases per 100 patient-years) in patients receiving romiplostim versus one case of cataracts reported in pooled control groups ( 0.9 cases per 100 patient-years) $[27,65]$. Although cataracts have not been reported with avatrombopag, none of the TPO-RAs require regular monitoring for cataracts. Importantly, multiple confounding factors such as steroid use in patients with ITP preclude any firm conclusions about a potential relationship between use of any TPO-RA and cataracts in humans [27-31]. Adverse events of special interest with TPO-RAs across trials are summarized in Table 4 [27-31, 61, 64-68].

\section{Other Uses of TPO-RAs}

\subsection{TPO-RAs in Chronic Liver Disease and Perioperative Use}

Avatrombopag and lusutrombopag are approved for the treatment of thrombocytopenia in adults with chronic liver disease who are scheduled to undergo a procedure [28, 29]. Avatrombopag was evaluated in the ADAPT-1 and ADAPT 2 studies. In both studies, patients were assessed for

Table 4 Adverse events of TPO-RAs for ITP reported in clinical trials [27-31, 61, 64-68]

\begin{tabular}{|c|c|c|c|}
\hline & Avatrombopag & Eltrombopag & Romiplostim \\
\hline Reticulin fibrosis & Not reported & $6 \%$ of patients in a 2 -year follow-up & $\begin{array}{l}6 \%(8 / 142) \text { over a median of } 69 \text { weeks of follow- } \\
\text { up }\end{array}$ \\
\hline $\begin{array}{l}\text { Thrombosis/thromboem- } \\
\text { bolic events (arterial or } \\
\text { venous) }\end{array}$ & $7 \%(9 / 128)$ & $6 \%(46 / 763)$ & $5.9 \%(39 / 653)$ \\
\hline Hepatic transaminitis & $\begin{array}{l}\text { ALT (3.1\%), AST } \\
(2.3 \%), \text { GGT } \\
(2.3 \%)^{\mathrm{a}}\end{array}$ & ALT (5\%), AST (4\%), and bilirubin (4\%) & Not reported \\
\hline Iron studies & No chelating ability & Chelates with calcium and iron & No chelating ability \\
\hline Cataracts & Not reported & $7 \%$ & $\begin{array}{l}\text { Up to } 9 \% \text { in an } 8 \text {-year follow-up; } 2.2 \text { cases per } 100 \\
\text { patient-years in a pooled analysis }\end{array}$ \\
\hline Skin pigmentation changes & Not reported & $\begin{array}{l}\text { Postmarketing reports of hyperpigmen- } \\
\text { tation and skin yellowing }\end{array}$ & Not reported \\
\hline
\end{tabular}

$A L T$ alanine aminotransferase, AST aspartate aminotransferase, GGT gamma-glutamyl transferase, ITP immune thrombocytopenia, TPO-RA thrombopoietin receptor agonist

${ }^{a}$ No increases in bilirubin were observed in a pooled analysis [58] 
eligibility during the 2 weeks prior to study randomization and were assigned to cohorts of high or low baseline platelet counts. Patients were randomized in a 2:1 ratio to receive avatrombopag $40 \mathrm{mg}$ daily for 5 days in patients with high baseline platelet counts (i.e., $40 \times 10^{9} / \mathrm{L}$ to $<50 \times 10^{9} / \mathrm{L}$ ) and $60 \mathrm{mg}$ daily for 5 days in patients with low baseline platelet counts (i.e., $<40 \times 10^{9} / \mathrm{L}$ ) or a matching placebo. The procedure was scheduled to take place 10-13 days after the initiation of avatrombopag (5-8 days after the last dose) [9, 28]. The primary end point in both studies was the proportion of patients who did not require a platelet transfusion or a rescue procedure to manage bleeding after randomization and for up to 7 days following an elective procedure [9].

In patients with low baseline platelet counts, a significantly higher rate of attainment of the primary end point occurred in the avatrombopag patients versus placebo in ADAPT-1 (66\% vs $23 \%$; $p<0.0001)$ and ADAPT-2 $(69 \%$ vs $35 \% ; p<0.0006)$. Of note, according to these data, roughly one out of three patients may not meet the platelet goal, which may prevent them from moving forward with the planned procedure or may require platelet transfusion to proceed. In patients with high baseline platelet counts, a significantly higher rate of attainment of the primary end point was observed in the avatrombopag patients versus placebo ADAPT-1 (88\% vs $38 \% ; p<0.0001)$ and ADAPT-2 $(88 \%$ vs 33\%; $p<0.0001)$ [9].

According to study authors, treatment-emergent adverse events in both ADAPT- 1 and ADAPT- 2 occurred at a rate similar to that observed with placebo [9]. Overall rates of treatment-emergent adverse events in ADAPT-1 were lower with avatrombopag versus placebo in patients with low baseline platelet counts $(59.6 \%$ vs $64.6 \%)$ and high baseline platelet counts (53.4\% vs $56.3 \%)$. Likewise, in ADAPT-2, rates of treatment-emergent adverse events were similar with avatrombopag and placebo in patients with low baseline platelet counts (51.4\% vs 51.2\%) and high baseline platelet counts (49.1\% vs $45.5 \%$ ) [9]. In a pooled analysis of ADAPT-1 and ADAPT-2, the most commonly reported treatment-emergent adverse events were pyrexia, abdominal pain, nausea, headache, upper abdominal pain, and procedural pain [69].

Lusutrombopag was evaluated in two placebo-controlled trials, L-PLUS-1 and L-PLUS-2, in which patients were treated with $3 \mathrm{mg}$ of lusutrombopag for up to 7 days prior to an invasive procedure that occurred 2-7 days after completion of the course of lusutrombopag [10, 11, 29]. At baseline, per inclusion criteria, patients had a baseline platelet count $<50 \times 10^{9} / \mathrm{L}[10,11]$. In the L-PLUS- 1 trial, patients with chronic liver disease with a planned invasive procedure were randomized in a 1:1 ratio to receive lusutrombopag $3 \mathrm{mg}$ or placebo. The primary end point of the proportion of patients who did not require a platelet transfusion prior to their procedure was significantly higher with lusutrombopag versus placebo (79.2\% vs $12.5 \%$ ) [10]. In the L-PLUS-2 trial, which had a similar design to L-PLUS-1, the percentage of patients who did not require platelet transfusion prior to the procedure was higher in patients receiving lusutrombopag versus placebo (64.8\% vs $29.0 \% ; p<0.0001)$ [11].

In the L-PLUS-1 trial, adverse drug reactions that may have been related to study drug occurred in a slightly higher percentage of patients receiving lusutrombopag versus placebo ( $8.3 \%$ vs $2.1 \%$ ) [10]. However, rates of treatmentemergent adverse events in the L-PLUS-2 trial were similar in the lusutrombopag and placebo arms (47.7\% vs $48.6 \%)$ [11]. Common adverse events occurring in $>3 \%$ of patients in L-PLUS-2 included headache, abdominal pain, fatigue, peripheral edema, and nausea [11], whereas the most common adverse events observed with lusutrombopag and placebo in L-PLUS-1 were postoperative fever, procedural pain, procedural hypertension, and increased aspartate aminotransferase [10]. Importantly, as with all TPO-RAs, it is important for patients to be monitored for post-operative thromboembolic complications [28, 29].

Some evidence supports use of TPO-RAs prior to other medical procedures when platelet transfusions are in limited supply and provided there is adequate lead time. In a recent case report by Lim and Gilreath published in 2020, periprocedural use of avatrombopag eliminated the need for pre-operative platelet transfusion in a 63-year-old man with chronic liver disease who was undergoing spinal decompression surgery. Because certain neurosurgical procedures require that patients meet a minimum platelet threshold (e.g., $100 \times 10^{9} / \mathrm{L}$ ), TPO-RAs have the potential to reduce the need for blood products. The patient initiated avatrombopag $20 \mathrm{mg}$ daily starting 4 weeks before surgery. After 2 weeks, when the platelet count target was not achieved, the dose was increased to $40 \mathrm{mg}$ three times weekly and $20 \mathrm{mg}$ daily administered on the remaining 4 days of each week. Avatrombopag raised platelet levels from $63 \times 10^{9} / \mathrm{L}$ to $100 \times$ $10^{9} / \mathrm{L}$ by the time of surgical intervention [70].

\subsection{Severe Aplastic Anemia}

Eltrombopag has been approved in combination with standard immunosuppressive therapy for the first-line treatment of adult and pediatric patients aged 2 years and older with severe aplastic anemia (SAA) [30]. Eltrombopag at a dose of $150 \mathrm{mg}$ daily combined with immunosuppressive therapy, consisting of a 4-day course of equine antithymocyte globulin and cyclosporine (based on ideal body weight), was evaluated in a phase I/II investigator-initiated trial evaluating three cohorts of patients with SAA with differing times to initiation of combined immunosuppressive therapy following onset of SAA (i.e., day 14 to month 6 in cohort 1 $[n=30]$, day 14 to month 3 in cohort $2[n=31]$, and day 1 to month 6 in cohort $3[n=31]$ ). Patients were evaluated 
for hematologic response, including complete response (i.e., absolute neutrophil count $\geq 1000$ per microliter, a hemoglobin level $\geq 10 \mathrm{~g} / \mathrm{dL}$, and a platelet count $\geq 100 \times 10^{9} / \mathrm{L}$ ) and partial response (i.e., no longer meeting SAA diagnostic criteria but without meeting all three complete response criteria). Complete response by month 6 occurred in 58\% of patients in cohort 3,26\% of patients in cohort 2 , and $33 \%$ of patients in cohort 1 . Notably, the overall response rate (complete and partial response) at month 6 in cohort 3 was $80 \%$, which was significantly higher than the $66 \%$ overall response rate observed in a historical cohort of 102 patients with SAA who received antithymocyte globulin and cyclosporine alone [71]. Although eltrombopag is approved for use in combination with standard immunosuppressive therapy in adults and children aged 2 years and older with severe aplastic anemia, a recent subgroup analysis of 40 pediatric patients receiving eltrombopag plus immunosuppressive therapy versus a historical cohort of 87 children receiving immunosuppressive therapy alone did not identify a significant improvement in overall response rates $(70 \%$ with eltrombopag plus immunosuppressive therapy versus $72 \%$ in the historical cohort of children receiving immunosuppressive therapy alone; $p=0.78)[30,72]$.

The most common adverse events occurring in $\geq 20 \%$ of patients treated with eltrombopag in an open-label clinical trial of adults with refractory SAA were nausea, fatigue, cough, diarrhea, and headache [30]. When combined with antithymocyte globulin and cyclosporine, severe adverse events attributed to eltrombopag in 92 patients with SAA included liver test abnormalities (18\%), abdominal pain (2\%), maculopapular rash (2\%), and pruritus (1\%) [71]. Importantly, patients taking $\geq 150 \mathrm{mg} /$ day should be cautioned that skin and eye hyperpigmentation may occur, owing to either iron-chelation properties of eltrombopag leading to a transient, drug-dependent, hemochromatosislike effect, or due to the drug distribution and discoloring effect of the molecule itself in these various tissues [73].

\subsection{Myelodysplastic Syndrome}

Studies into the efficacy of TPO-RAs in MDS failed to show a survival benefit and indicated some potential for harm as a result of a potential increase in progression to leukemia [27]. The Study of Eltrombopag in Myelodysplastic Syndromes Receiving Azacitidine (SUPPORT) phase III trial did not identify a progression-free survival or overall survival benefit with eltrombopag plus azacitidine versus placebo plus azacitidine. Although the risk of death or progression to acute myeloid leukemia was not elevated with combination therapy, the risk of serious adverse events and adverse events leading to discontinuation were higher with combination therapy. It is important to alert prescribers of this combination to the potential for increased risk of adverse events without added clinical benefit [74].

\subsection{Post-Hematopoietic Stem-Cell Transplant}

Persistent isolated thrombocytopenia often occurs after allogeneic hematopoietic stem-cell transplantation (allogeneic SCT) and may increase the risk of adverse transplant outcomes. Secondary failure of platelet recovery (SFPR) may be defined as platelet counts $<20 \times 10^{9} / \mathrm{L}$ for 7 days consecutively or a need for transfusion in patients with a platelet count $\geq 50 \times 10^{9} / \mathrm{L}$ who did not require transfusion in the 7 days following SCT. Although there is no well-established standard of care in SFPR management, patients may receive supportive care. Platelet transfusion may be used in some cases; however, adverse events may occur, such as fluid overload, infusion-related reactions, infection, or refractoriness to subsequent platelet transfusions. TPO-RAs have been used as off-label treatment for these conditions with variable results [75]. Table 5 provides efficacy and safety data from a compilation of various clinical trials and meta-analyses using these treatments [75-79].

\subsection{Chemotherapy-Induced Thrombocytopenia}

Chemotherapy-induced thrombocytopenia (CIT) is a serious complication of chemotherapy in cancer patients resulting in low platelet counts that may necessitate the reduction of chemotherapy doses, cycle delays, or a change in chemotherapy regimen, all of which may compromise long-term outcomes. In December 2019, the US FDA granted avatrombopag Orphan Drug Designation for the treatment of patients with CIT [80, 81].

In a phase III trial of avatrombopag to study its efficacy in CIT (NCT03471078), avatrombopag increased platelet counts as anticipated and as demonstrated in other populations of patients experiencing thrombocytopenia; however, the placebo group performed unexpectedly well with strong platelet count rebound prior to chemotherapeutic dose and few patients requiring platelet transfusions or chemotherapy dose modifications. Although initial results of the trial were negative on the primary composite outcome (i.e., the proportion of subjects who did not require platelet transfusion, a $\geq 15 \%$ reduction in the dose of chemotherapy, or delay of chemotherapy administration by $\geq 4$ days), of note, the study excluded patients with grade 2 or higher chemotherapy-induced thrombocytopenia (other than the current chemotherapy regimen) within 6 months of screening and patients who had received more than two previous lines of chemotherapy. Moreover, the study evaluated patients with isolated, nadir thrombocytopenia and did not separately evaluate patients with more severe or persistent CIT, such 


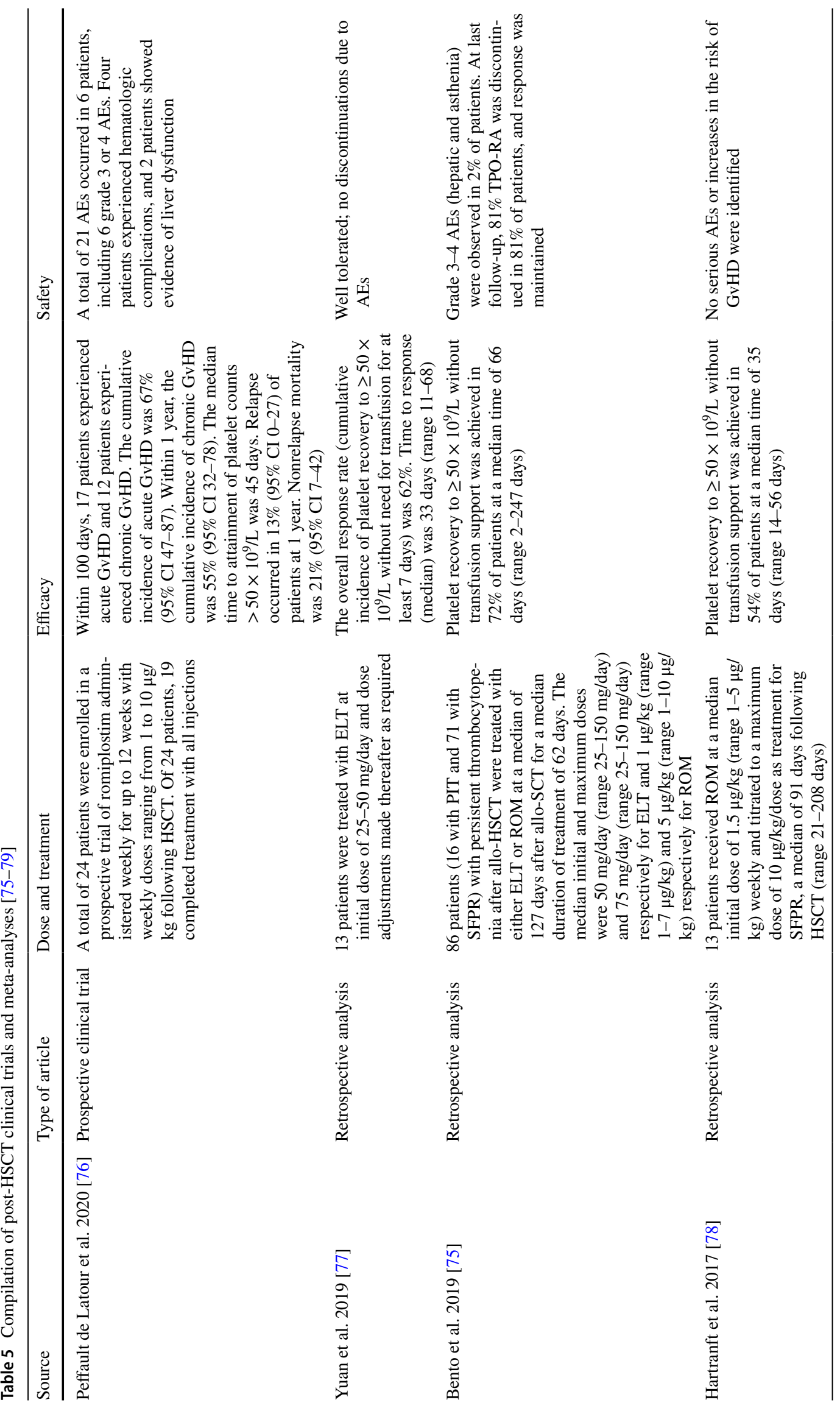




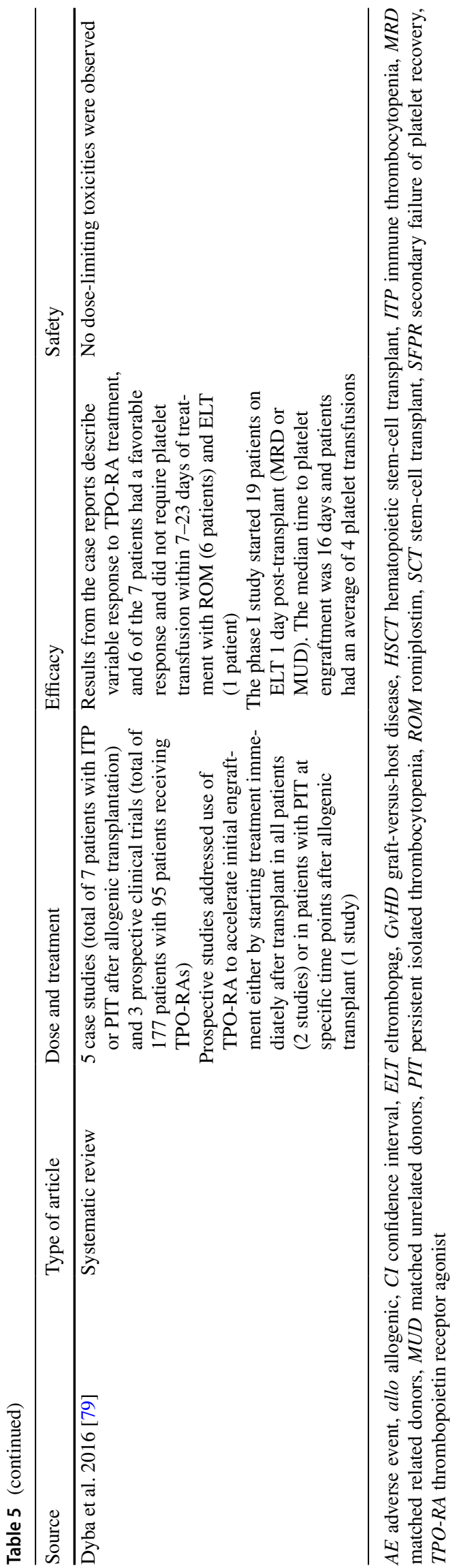

as CIT that continued despite adequate time for recovery of white blood cell counts [80, 82].

Current treatment options for CIT are limited [83]. However, some data support the efficacy of TPO-RAs in CIT. A retrospective study published by Al-Samkari et al. in 2020 evaluated use of romiplostim for CIT across four centers. In this study, patients were evaluated on a primary outcome of attainment of platelet counts $\geq 75 \times 10^{9} / \mathrm{L}$, with an increase of $\geq 30 \times 10^{9} / \mathrm{L}$ from baseline levels. A total of 173 patients with cancer were included in the study, including 153 patients with solid tumors. Over a median of four cycles (range: 1-36 cycles) of chemotherapy administered concurrently with romiplostim, response consistent with the primary efficacy outcome occurred in $71 \%$ of patients. Furthermore, $79 \%$ of patients did not require chemotherapy dose reductions or treatment delays, and $89 \%$ of patients did not require platelet transfusion [84].

Further studies of TPO-RAs in CIT are ongoing, including a study of avatrombopag in patients with any of several malignant tumor types (NCT04609891) [85], a study of avatrombopag in patients with thrombocytopenia after a hematopoietic stem-cell transplant (NCT04312789) [86], a study of romiplostim for CIT in pediatric patients with solid tumors undergoing myelosuppressive chemotherapy (NCT04671901) [87], and a study of romiplostim in patients with lymphoma receiving standard chemotherapy for lymphoma (NCT04673266) [88]. Romiplostim for CIT management is also being studied in non-small-cell lung cancer and gynecologic malignancies (NCT03937154) [89] as well as in gastrointestinal malignancies (NCT03362177) [90]. The optimal population for potential use of TPO-RAs in CIT requires further study.

\section{Conclusions}

In evaluating the characteristics of TPO-RAs, pharmacists should take into account not only efficacy and safety data but also patient preferences for route of administration, the need for stable platelet count control, and whether dietary restrictions pose an issue. Although strong data support the use of TPO-RAs in ITP, chronic liver disease, and a variety of other disease states, taking into account the pharmacokinetic, pharmacodynamic, and mechanistic characteristics of these agents is important. Analyzing the onset of action based on available data may also be relevant in therapeutic decisions. In addition, the cost of therapy may be taken into account across the useful dosage range of available agents. Pharmacists should counsel patients on the risk of thromboembolic complications and the relative risk of adverse events of special interest with TPO-RAs such as liver enzyme elevations. Through an in-depth knowledge of the TPO-RA class, pharmacists can better serve patients and other health 
care professionals, aiding in appropriate decisions across health systems and for individual patients.

Acknowledgements Medical writing support and literature search were provided by Michael R. Page, PharmD, RPh, Vaidehee Deshpande, $\mathrm{PhD}$, and Sarah Bubeck, PhD of BioCentric, Inc (Collingswood, NJ, USA). The development of this manuscript was supported by funding from Dova Pharmaceuticals, a Sobi company (Durham, NC, USA).

\section{Declarations}

Funding Medical writing support and literature search were provided by Michael R. Page, PharmD, RPh, Vaidehee Deshpande, PhD, and Sarah Bubeck, PhD of BioCentric, Inc. (Collingswood, NJ, USA). The development of this manuscript was supported by funding from Dova Pharmaceuticals, a Sobi company (Durham, NC, USA).

Conflict of interest JG: No relevant conflicts of interest. ML: No relevant conflicts of interest. JB: No relevant conflicts of interest.

Ethics approval Not applicable.

Consent to participate Not applicable.

Consent for publication Not applicable.

Availability of data and material Not applicable.

Code availability Not applicable.

Author contributions Authors contributed equally to the writing of the manuscript and provided extensive revisions.

Open Access This article is licensed under a Creative Commons Attribution-NonCommercial 4.0 International License, which permits any non-commercial use, sharing, adaptation, distribution and reproduction in any medium or format, as long as you give appropriate credit to the original author(s) and the source, provide a link to the Creative Commons licence, and indicate if changes were made. The images or other third party material in this article are included in the article's Creative Commons licence, unless indicated otherwise in a credit line to the material. If material is not included in the article's Creative Commons licence and your intended use is not permitted by statutory regulation or exceeds the permitted use, you will need to obtain permission directly from the copyright holder. To view a copy of this licence, visit http://creativecommons.org/licenses/by-nc/4.0/.

\section{References}

1. Kaushansky K. The molecular mechanisms that control thrombopoiesis. J Clin Invest. 2005;115(12):3339-47. https://doi.org/ 10.1172/JCI26674.

2. Kaushansky K. Thrombopoietin and its receptor in normal and neoplastic hematopoiesis. Thromb J. 2016;14(suppl 1):40. https:// doi.org/10.1186/s12959-016-0095-z.

3. Kato T, Matsumoto A, Ogami K, Tahara T, Morita H, Miyazaki H. Native thrombopoietin: structure and function. Stem Cells. 1998;16(5):322-8. https://doi.org/10.1002/stem.160322.

4. Neunert CE, Terrell DR, Arnold DM, Buchanan G, Cines DB, Cooper N, et al. American Society of Hematology 2019 guidelines for immune thrombocytopenia. Am Soc Hematol. 2019;3(23):3829-66. https://doi.org/10.1182/bloodadvances. 2019000966.

5. Provan D, Arnold DM, Bussel JB, Chong BH, Cooper N, Gernsheimer $\mathrm{T}$, et al. Updated international consensus report on the investigation and management of primary immune thrombocytopenia. Blood Adv. 2019;3(22):3780-817. https://doi.org/10.1182/ bloodadvances.2019000812.

6. Jurczak W, Chojnowski K, Mayer J, Krawczyk K, Jamieson BD, Tian W, et al. Phase 3 randomised study of avatrombopag, a novel thrombopoietin receptor agonist for the treatment of chronic immune thrombocytopenia. Br J Haematol. 2018;183(3):479-90. https://doi.org/10.1111/bjh.15573.

7. Cheng G, Saleh MN, Marcher C, Vasey S, Mayer B, Aivado M, et al. Eltrombopag for management of chronic immune thrombocytopenia (RAISE): a 6-month, randomised, phase 3 study. Lancet. 2011;377(9763):393-402. https://doi.org/10.1016/S01406736(10)60959-2.

8. Kuter DJ, Bussel JB, Lyons RM, Pullarkat V, Gernsheimer TB, Senecal FM, et al. Efficacy of romiplostim in patients with chronic immune thrombocytopenic purpura: a double-blind randomised controlled trial. Lancet. 2008;371(9610):395-403. https://doi.org/ 10.1016/S0140-6736(08)60203-2.

9. Terrault N, Chen YC, Izumi N, Kayali Z, Mitrut P, Tak WY, et al. Avatrombopag before procedures reduces need for platelet transfusion in patients with chronic liver disease and thrombocytopenia. Gastroenterology. 2018;155(3):705-18. https://doi.org/10. 1053/j.gastro.2018.05.025.

10. Hidaka H, Kurosaki M, Tanaka H, Kudo M, Abiru S, Igura T, et al. Lusutrombopag reduces need for platelet transfusion in patients with thrombocytopenia undergoing invasive procedures. Clin Gastroenterol Hepatol. 2019;17(6):1192-200. https://doi.org/ 10.1016/j.cgh.2018.11.047.

11. Peck-Radosavljevic M, Simon K, Iacobellis A, Hassanein T, Kayali Z, Tran A, et al. Lusutrombopag for the treatment of thrombocytopenia in patients with chronic liver disease undergoing invasive procedures (L-PLUS 2). Hepatology. 2019;70(4):1336-48. https://doi.org/10.1002/hep.30561.

12. Iino M, Sakamoto $Y$, Sato T. Treatment-free remission after thrombopoietin receptor agonist discontinuation in patients with newly diagnosed immune thrombocytopenia: an observational retrospective analysis in real-world clinical practice. Int J Hematol. 2020;112(2):159-68. https://doi.org/10.1007/ s12185-020-02893-y.

13. Deuson R, Danese M, Mathias SD, Schoonen M, Fryzek J. The burden of immune thrombocytopenia in adults: evaluation of the thrombopoietin receptor agonist romiplostim. J Med Econ. 2012;15(5):956-76. https://doi.org/10.3111/13696998.2012. 688902.

14. Cines DB, Bussel JB, Liebman HA, Luning Prak ET. The ITP syndrome: pathogenic and clinical diversity. Blood. 2009;113(26):6511-21. https://doi.org/10.1182/ blood-2009-01-129155.

15. Kelton JG, Vrbensky JR, Arnold DM. How do we diagnose immune thrombocytopenia in 2018? Hematol Am Soc Hematol Educ Program. 2018;2018(1):561-7. https://doi.org/10.1182/ asheducation-2018.1.561.

16. Rodeghiero F, Stasi R, Gernsheimer T, Michel M, Provan D, Arnold DM, et al. Standardization of terminology, definitions and outcome criteria in immune thrombocytopenic purpura of adults and children: report from an international working group. Blood. 2009;113(11):2386-93. https://doi.org/10.1182/ blood-2008-07-162503.

17. Al-Samkari H, Kuter DJ. Optimal use of thrombopoietin receptor agonists in immune thrombocytopenia. Ther Adv Hematol. 
2019;10:2040620719841735. https://doi.org/10.1177/2040620719 841735.

18. Varghese LN, Defour J-P, Pecquet C, Constantinescu SN. The thrombopoietin receptor: structural basis of traffic and activation by ligand, mutations, agonists and mutated calreticulin. Front Endocrinol (Lausanne). 2017;8:59. https://doi.org/10.3389/fendo. 2017.00059.

19. Grozovsky R, Giannini S, Falet H, Hoffmeister KM. Novel mechanisms of platelet clearance and thrombopoietin regulation. Curr Opin Hematol. 2015;22(5):445-51. https://doi.org/10.1097/MOH. 000000000000170.

20. Fukushima-Shintani M, Suzuki K, Iwatsuki Y, Abe M, Sugasawa K, Hirayama F, et al. AKR-501 (YM477) a novel orally-active thrombopoietin receptor agonist. Eur J Haematol. 2009;82(4):247-54. https://doi.org/10.1111/j.1600-0609.2008. 01198.x.

21. Swinkels M, Rijkers M, Voorberg J, Vidarsson G, Leebeek FWG, Jansen AJG. Emerging concepts in immune thrombocytopenia. Front Immunol. 2018;9:880. https://doi.org/10.3389/fimmu.2018. 00880 .

22. Grozovsky R, Giannini S, Falet H, Hoffmeister KM. Regulating billions of blood platelets: glycans and beyond. Blood. 2015;126(16):1877-84. https://doi.org/10.1182/ blood-2015-01-569129.

23. Nurden AT, Viallard J-F, Nurden P. New-generation drugs that stimulate platelet production in chronic immune thrombocytopenia purpura. Lancet. 2009;373(9674):1562-8. https://doi.org/10. 1016/S0140-6736(09)60255-5.

24. Krause DS. IFN- $\gamma$ binds to TPO to inhibit hematopoiesis. Blood. 2019;133(19):2004-5. https://doi.org/10.1182/ blood-2019-03-900977.

25. Onisâi M, Vlădăreanu AM, Spînu A, Găman M, Bumbea H. Idiopathic thrombocytopenic purpura (ITP) - new era for an old disease. Rom J Intern Med. 2019;57(4):273-83. https://doi.org/10. 2478/rjim-2019-0014.

26. Bussel JB, Kuter DJ, Aledort LM, Kessler CM, Cuker A, Pendergrass $\mathrm{KB}$, et al. A randomized trial of avatrombopag, an investigational thrombopoietin-receptor agonist, in persistent and chronic immune thrombocytopenia. Blood. 2014;123(25):3887-94. https://doi.org/10.1182/blood-2013-07-514398.

27. Ghanima W, Cooper N, Rodeghiero F, Godeau B, Bussel JB. Thrombopoietin receptor agonists: ten years later. Haematologica. 2019;104(6):1112-23. https://doi.org/10.3324/haematol.2018. 212845.

28. Doptelet. Package insert. Dova Pharmaceuticals Inc; 2018.

29. Mulpleta. Package insert. Shionogi Inc; 2018.

30. Promacta. Package insert. GlaxoSmithKline; 2018.

31. NPLATE. Package insert. Amgen Inc; 2018.

32. González-López TJ, Alvarez-Román MT, Pascual C, SánchezGonzález B, Fendández-Fuentes F, Jarque I, et al. Eltrombopag safety and efficacy for primary chronic immune thrombocytopenia in clinical practice. Eur J Haematol. 2016;97(3):297-302. https:// doi.org/10.1111/ejh.12725.

33. Cheloff AZ, Al-Samkari H. Avatrombopag for the treatment of immune thrombocytopenia and thrombocytopenia of chronic liver disease. J Blood Med. 2019;10:312-21. https://doi.org/10.2147/ JBM.S191790.

34. Li C, Li X, Huang F, Yang J, Wu A, Wang L, et al. Efficacy and safety of avatrombopag in patients with thrombocytopenia: a systematic review and meta-analysis of randomized controlled trials. Front Pharmacol. 2019;10:829. https://doi.org/10.3389/fphar. 2019.00829.

35. Al-Samkari H, Tian W, Kuter DJ. Baseline endogenous thrombopoietin concentrations and response to avatrombopag in immune thrombocytopenia. Abstract presented at: International Society on Thrombosis and Hemostasis Congress; July 6-10,
2019; Melbourne, Australia. Abstract PB0399. Accessed March 6, 2021. https://academy.isth.org/isth/2019/melbourne/263585/ david.kuter.baseline.endogenous.thrombopoietin.concentrations. and.response.to.html.

36. NPLATE. Summary of Product Characteristics. Amgen Europe, BV; 2013.

37. Gilreath JA, Wei M, Paul S, Parker CJ, Stenehjem DD, Rodgers GM. Dynamic dosing of romiplostim in patients with immune thrombocytopenia purpura: two case reports. J Oncol Pharm Pract. 2019;25(3):719-23. https://doi.org/10.1177/1078155217752536.

38. Bussel JB, Cheng G, Saleh MN, Psaila B, Kovaleva L, Meddeb B, et al. Eltrombopag for the treatment of chronic idiopathic thrombocytopenic purpura. N Engl J Med. 2007;357(22):2237-47. https://doi.org/10.1056/NEJMoa073275.

39. González-Porras JR, Godeau B, Carpenedo M. Switching thrombopoietin receptor agonist treatments in patients with primary immune thrombocytopenia. Ther Adv Hematol. 2019;10:2040620719837906. https://doi.org/10.1177/20406 20719837906

40. Khellaf M, Viallard J-F, Hamidou M, Cheze S, Roudot-Thoraval $\mathrm{F}$, Lefrere F, et al. A retrospective pilot evaluation of switching thrombopoietic receptor-agonists in immune thrombocytopenia. Hematologica. 2013;98(6):881-7. https://doi.org/10.3324/ haematol.2012.074633.

41. Nazi I, Kelton JG, Larché M, Snider D, Heddle NM, Crowther MA, et al. The effect of rituximab on vaccine responses in patients with immune thrombocytopenia. Blood. 2013;122(11):1946-53. https://doi.org/10.1182/ blood-2013-04-494096.

42. Travelers' health: destinations. Centers for Disease Control and Prevention. https://wwwnc.cdc.gov/travel/destinations/list. Accessed 4 Mar 2021.

43. Cooper N, Kruse A, Kruse C, Watson S, Morgan M, Bussel JB, et al. Results from the ITP World IMPACT Survey (I-WISh): patients with immune thrombocytopenia (ITP) experience impaired quality of life $(\mathrm{QoL})$ regarding daily activities, social interactions, emotional well-being and working lives. Blood. 2018;132(suppl 1):4804. https://ashpublications.org/blood/article/ 132/Supplement\%201/4804/262467/Results-from-the-ITP-WorldIMPACT-Survey-I-WISh. Accessed 6 Mar 2021.

44. Shimano KA, Neunert C, Bussel JB, Klaassen RJ, Bhat R, Pastore YD, et al. Quality of life is an important indication for secondline treatment in children with immune thrombocytopenia. Pediatr Blood Cancer. 2021;68(6): e29023. https://doi.org/10.1002/pbc. 29023.

45. Williams DD, Peng B, Bailey CK, Wire MB, Deng Y, Park $\mathrm{JW}$, et al. Effects of food and antacids on the pharmacokinetics of eltrombopag in healthy adult subjects: two single-dose, open-label, randomized-sequence, crossover studies. Clin Ther. 2009;31(4):764-76. https://doi.org/10.1016/j.clinthera.2009.04. 010.

46. Wire MB, Bruce J, Gauvin J, Pendry CJ, McGuire S, Qian Y, et al. A randomized, open-label, 5-period, balanced crossover study to evaluate the relative bioavailability of eltrombopag powder for oral suspension (PfOS) and tablet formulations and the effect of a high-calcium meal on eltrombopag pharmacokinetics when administered with or 2 hours before or after PfOS. Clin Ther. 2012;34(3):699-709. https://doi.org/10.1016/j.clinthera.2012.01. 011.

47. Nomoto M, Pastino G, Rege B, Aluri J, Ferry J, Han D. Pharmacokinetics, pharmacodynamics, pharmacogenomics, safety, and tolerability of avatrombopag in healthy Japanese and white subjects. Clin Pharmacol Drug Dev. 2018;7(2):188-95. https://doi. org/10.1002/cpdd.349.

48. Agarwal N, Mangla A. Thrombopoietin receptor agonist for treatment of immune thrombocytopenia in pregnancy: a narrative 
review. Ther Adv Hematol. 2021. https://doi.org/10.1177/20406 207211001139.

49. Grace RF, Aggarwal K, Vredenburg M, Despotovic JM. Stability of crushed avatrombopag tablets demonstrated in multiple food vehicles. Abstract presented at: International Society on Thrombosis and Hemostasis Congress; July 12-14, 2020; Virtual Congress. Abstract PB1353. https://abstracts.isth.org/abstract/stability-ofcrushed-avatrombopag-tablets-demonstrated-in-multiple-foodvehicles/. Accessed 20 Oct 2020.

50. Lexicomp. Doptelet (avatrombopag). Accessed March 5, 2021.

51. Lexicomp. Promacta (eltrombopag). Accessed March 5, 2021.

52. Lexicomp. Nplate (rompiplostim). Accessed March 5, 2021.

53. Lexicomp. Mulpleta (lusutrombopag). Accessed March 5, 2021.

54. EMA. Doptelet, INN (avatrombopag). https://www.ema.europa. eu/en/documents/product-information/doptelet-epar-product-infor mation_en.pdf. Accessed 21 May 2021.

55. EMA. Revolade, INN (eltrombopag). https://www.ema.europa. eu/en/documents/product-information/revolade-epar-productinformation_en.pdf. Accessed 21 May 2021.

56. EMA. Mulpleo, INN (lusutrombopag). https://www.ema.europa. eu/en/documents/product-information/mulpleo-epar-productinformation_en.pdf. Accessed 21 May 2021.

57. EMA. Nplate, INN (romiplostim). https://www.ema.europa.eu/ en/documents/product-information/nplate-epar-product-infor mation_en.pdf. Accessed 21 May 2021.

58. CDER. https://www.accessdata.fda.gov/drugsatfda_docs/nda/ 2018/210238Orig 1s000OtherR.pdf. Published February 27, 2018. Accessed March 10, 2021.

59. FDA. Risk Evaluation and Mitigation Strategies: REMS. https:// www.fda.gov/drugs/drug-safety-and-availability/risk-evalu ation-and-mitigation-strategies-rems. Published August 8, 2019. Accessed 10 Mar 2021.

60. Worthy SL. Don't sell out safety: a call to preserve risk evaluation and mitigation strategies to reduce harm to patients and the public in the US. J Pharm Policy Prac. 2016;9:2. https://doi. org/10.1186/s40545-016-0051-0.

61. Rodeghiero F, Stasi R, Giagounidis A, Viallard J-F, Godeau B, Pabinger I, et al. Long-term safety and tolerability of romiplostim in patients with primary immune thrombocytopenia: a pooled analysis of 13 clinical trials. Eur J Haematol. 2013;91(5):423-36. https://doi.org/10.1111/ejh.12181.

62. Wong RSM, Saleh MN, Khelif A, Salama A, Portella MSO, Burgess P, et al. Safety and efficacy of long-term treatment of chronic/persistent ITP with eltrombopag: final results of the EXTEND study. Blood. 2017;130(23):2527-36. https://doi.org/ 10.1182/blood-2017-04-748707.

63. Kuter DJ, Newland A, Chong BH, Rodeghiero F, Romero MT, Pabinger I, et al. Romiplostim in adult patients with newly diagnosed or persistent immune thrombocytopenia (ITP) for up to 1 year and in those with chronic ITP for more than 1 year: a subgroup analysis of integrated data from completed romiplostim studies. Br J Haematol. 2019;185(3):503-13. https://doi.org/10. 1111/bjh.15803.

64. Bussel J, Allen LF, Aggarwal K, Vredenburg M, Tian W, Liebman H. Lack of clinically significant hepatotoxicity in patients with chronic immune thrombocytopenia (c-ITP) treated with the novel, oral thrombopoietin receptor agonist avatrombopag: pooled safety analysis of four clinical trials. ISTH Academy. July 7, 2019. https://academy.isth.org/isth/2019/melbourne/ 263604/michael.vredenburg.lack.of.clinically.significant.hepat otoxicity.in.patients.html?f=menu\%3D14\%2Abrowseby\%3D8\% 2Asortby\%3D2\%2Amedia\%3D2\%2Atopic\%3D21465. Accessed 21 Oct 2020

65. Cines DB, Gernsheimer T, Wasser J, Godeau B, Provan D, Lyons $\mathrm{R}$, et al. Integrated analysis of long-term safety in patients with chronic immune thrombocytopaenia (ITP) treated with the thrombopoietin (TPO) receptor agonist romiplostim. Int J Hematol. 2015;102(3):259-70. https://doi.org/10.1007/ s12185-015-1837-6.

66. Brynes RK, Wong RS, Thein MM, Bakshi KK, Burgess P, Theodore D, et al. A 2-year, longitudinal, prospective study of the effects of eltrombopag on bone marrow in patients with chronic immune thrombocytopenia. Acta Haematol. 2017;137(2):66-72. https://doi.org/10.1159/000452992.

67. Bussel JB, Kuter DJ, Pullarkat V, Lyons RM, Guo M, Nichol JL. Safety and efficacy of long-term treatment with romiplostim in thrombocytopenic patients with chronic ITP. Blood. 2009;113(10):2161-71. https://doi.org/10.1182/ blood-2008-04-150078.

68. Neunert CE, Rose NJ. Romiplostim for the management of pediatric immune thrombocytopenia: drug development and current practice. Blood Adv. 2019;3(12):1907-15. https://doi.org/10. 1182/bloodadvances. 2019000279.

69. Poordad F, Terrault NA, Alkhouri N, Tian W, Allen LF, Rabinovitz M. Avatrombopag, an alternate treatment option to reduce platelet transfusions in patients with thrombocytopenia and chronic liver disease-integrated analyses of 2 phase 3 studies. Int $\mathbf{J}$ Hepatol. 2020;2020:5421632. https://doi.org/10.1155/2020/54216 32.

70. Lim MY, Gilreath JA. Periprocedural use of avatrombopag for neurosurgical interventions: a strategy to avoid platelet utilization. Blood Adv. 2020;4(18):4438-41. https://doi.org/10.1182/blood advances. 2020003045.

71. Townsley DM, Scheinberg P, Winkler T, Desmond R, Dumitriu B, Rios O, et al. Eltrombopag added to standard immunosuppression for aplastic anemia. N Engl J Med. 2017;376(16):1540-50. https:// doi.org/10.1056/NEJMoa1613878.

72. Groarke EM, Patel BA, Gutierrez-Rodrigues F, Rios O, Lotter J, Baldoni D, et al. Eltrombopag added to immunosuppression for children with treatment-naïve severe aplastic anaemia. Br J Haematol. 2021;192(3):605-14. https://doi.org/10.1111/bjh.17232.

73. Rodgers GM, Kurtti AL, Gilreath JA. Are eltrombopag plasma and skin hyperpigmentation related? The eyes have it. Am J Hematol. 2019;94(3):394-5. https://doi.org/10.1002/ajh.25169.

74. Dickinson M, Cherif H, Fenaux P, Mittelman M, Verma A, Portella MSO, et al. Azacitidine with or without eltrombopag for first-line treatment of intermediate- or high-risk MDS with thrombocytopenia. Blood. 2018;132(25):2629-38. https://doi.org/10. 1182/blood-2018-06-855221.

75. Bento L, Bastida JM, Garcia-Cadenas I, Rivera D, Bosch-Vilaseca A, et al. Thrombopoietin receptor agonists for severe thrombocytopenia after allogenic stem cell transplantation: experience of the Spanish group of hematopoietic stem cell transplant. Biol Blood Marrow Transplant. 2019;25(9):1825-31. https://doi.org/ 10.1016/j.bbmt.2019.05.023.

76. de Latour RP, Chevret S, Ruggeri AL, Suarez F, Souchet L, Michonneau D, et al. Romiplostim in patients undergoing hematopoietic stem cell transplantation: results of a phase $1 / 2$ multicenter trial. Blood. 2020;135(3):227-9. https://doi.org/10.1182/ blood.2019000358.

77. Yuan C, Boyd AM, Nelson J, Patel RD, Varela JC, Goldstein $\mathrm{SC}$, et al. Eltrombopag for treating thrombocytopenia after allogenic stem cell transplantation. Biol Blood Marrow Transplant. 2019;25(7):1320-4. https://doi.org/10.1016/j.bbmt.2019.01.027.

78. Hartranft ME, Clemmons AB, DeRemer DL, Kota V. Evaluation of romiplostim for the treatment of secondary failure of platelet recovery among allogeneic hematopoietic stem cell transplant patients. J Oncol Pharm Pract. 2017;23(1):10-7. https://doi.org/ 10.1177/1078155215612240.

79. Dyba J, Tinmouth A, Bredeson C, Matthews J, Allan DS. Eltrombopag after allogeneic haematopoietic cell transplantation in a case of poor graft function and systematic review of the literature. 
Transfus Med. 2016;26(3):202-307. https://doi.org/10.1111/tme. 12300.

80. Mones JV, Soff G. Management of thrombocytopenia in cancer patients. Cancer Treat Res. 2019;179:139-50. https://doi.org/10. 1007/978-3-030-20315-3_9.

81. FDA. Orphan Drug Designations and Approvals. https://www. accessdata.fda.gov/scripts/opdlisting/oopd/detailedIndex.cfm? cfgridkey $=325110$. Accessed 18 Jun 2021.

82. ClinicalTrials.gov. Avatrombopag for the Treatment of Chemotherapy-Induced Thrombocytopenia in Adults With Active NonHematological Cancers. https://clinicaltrials.gov/ct2/show/NCT03 471078. Accessed 18 Jun 2021.

83. Kuter DJ, Macahilig C, Grotzinger KM, Poston SA, Wang PF, Dawson KL, et al. Treatment patterns and clinical outcomes in patients with chronic immune thrombocytopenia (ITP) switched to eltrombopag or romiplostim. Int J Hematol. 2015;101(3):255-63. https://doi.org/10.1007/s12185-014-1731-7.

84. Al-Samkari H, Parnes AD, Goodarzi K, Weitzman JI, Connors JM, Kuter DJ. A multicenter study of romiplostim for chemotherapy-induced thrombocytopenia in solid tumors and hematologic malignancies. Haematologica. 2020. https://doi.org/10.3324/ haematol.2020.251900.
85. ClinicalTrials.gov. Avatrombopag on the treatment of thrombocytopenia induced by chemotherapy of malignant tumors. https:// clinicaltrials.gov/ct2/show/NCT04609891. Accessed 9 Mar 2021.

86. ClinicalTrials.gov. Avatrombopag for the treatment of thrombocytopenia after donor hematopoietic stem cell transplant. https:// clinicaltrials.gov/ct2/show/NCT04312789. Accessed 9 Mar 2021.

87. ClinicalTrials.gov. A Study of Romiplostim to Prevent Low Platelet Counts in Children and Young Adults Receiving Chemotherapy for Solid Tumors. https://clinicaltrials.gov/ct2/show/NCT04 671901. Accessed 9 Mar 2021.

88. ClinicalTrials.gov. Using romiplostim to treat low platelet counts during chemotherapy in people with lymphoma. https://clinicaltr ials.gov/ct2/show/NCT04673266. Accessed 9 Mar 2021.

89. ClinicalTrials.gov. Study of romiplostim for chemotherapyinduced thrombocytopenia in adult subjects with non-small cell lung cancer (NSCLC), ovarian cancer, or breast cancer. https:// clinicaltrials.gov/ct2/show/NCT03937154. Accessed 9 Mar 2021.

90. ClinicalTrials.gov. Study of romiplostim for chemotherapyinduced thrombocytopenia in adult subjects with gastrointestinal, pancreatic, or colorectal cancer. https://clinicaltrials.gov/ct2/ show/NCT03362177. Accessed 9 Mar 2021. 